\title{
SURGICAL TREATMENT OF RHIZARTHROSIS: TRAPEZIECTOMY WITH OR WITHOUT LIGAMENTOPLASTY VERSUS TOTAL PROSTHESIS
}

Claudia Santos ${ }^{1}$, Manuel Alexandre Pereira', Luis Fernando Nunes Pires Silva', Rui Miguel Teixeira Claro², Miguel Nuno Albuquerque Cardoso Trigueiros², Joaquim César Ferreira da Silva ${ }^{3}$

\section{ABSTRACT}

Objective: The aim of this study was to review cases that underwent surgical treatment using two techniques: trapeziectomy with or without ligamentoplasty and arthroplasty with implant. Methods: Fifty-two hands that were surgically treated for rhizarthrosis between 1995 and 2008 were evaluated: 32 cases of trapeziectomy with or without ligamentoplasty (group A) and 20 with implant arthroplasty (group B). The mean follow-up for group A was 72 months and for group B, 23 months. There were no significantly different results with regard to pain, activities of daily living, mobility or strength. In the radiographic evaluation, it was found that the scaphometacarpal height was better preserved in group B. The mean time taken to achieve recovery was 10 weeks in group $A$ and 4.5 in group B. Four cases with complications were recorded: one case of algoneurodystrophy in group A and two cases of dislocation and one case of fracture of the trapezium in group B. Results: The results from prostheses were better than the results from the traditional treatment for rhizarthrosis using trapeziectomy with or without ligamentoplasty because of the rapid recovery that prostheses provide. Conclusion: However, prostheses should be applied carefully, because there is a potential for complications relating to the implants.

Keywords - Osteoarthritis; Trapezium; Arthroplasty

\section{INTRODUCTION}

The concept of arthroplasty with implants arose in 1960 as an alternative to trapeziectomy, in order to avoid shortening and instability of the thumb ${ }^{(1,3)}$. In 1970, Swanson introduced silicone implants, which were then rapidly abandoned because they caused bone erosion and marked synovitis. Today, this method is reserved for a few cases of rheumatoid arthritis. In 1979, Caffiniére published the first study on total prostheses of the trapezium-metacarpal, using a design similar to that of hip prostheses, with a polyethylene cup in the trapezium that articulates with the head of a metal component in the first metacarpal ${ }^{(1,2)}$.

This innovation in surgical treatment for rhizarthrosis led to great controversy, since there were few studies that would demonstrate the superiority of arthroplasty over trapeziectomy. The recovery time seems to be shorter in cases of prostheses, but the durability of the implants remains unknown ${ }^{(4)}$.

Through this study, the aim was to compare the clinical and radiographic results between trapeziectomy with or without ligamentoplasty and arthroplasty with an implant of ball-and-socket type, for treating idiopathic rhizarthrosis.

1 - Complementary Clinician in the Orthopedics Service, Hospital Santo António, Porto, Portugal.

2 - Hospital Attending Physician in the Orthopedics Service, Hospital Santo António, Porto, Portugal.

3 - Hospital Attending Physician specializing in Orthopedics, Orthopedics Service, Hospital Santo António, Porto, Portugal.

Work performed at the Orthopedics Service, Hospital Santo António, Hospital Center of Porto, Porto, Portugal.

Correspondence: Serviço de Ortopedia, Hospital Santo António - Largo Professor Abel Salazar - 4099-001 - Porto, Portugal. E-mail: claudsantos@hotmail.com

Work received for publication: April 14, 2010; accepted for publication: November 4, 2010. 


\section{MATERIAL AND METHODS}

Between January 1995 and October 2008, operations were performed on 74 patients with grades III and IV rhizarthrosis, according to the classification of Eaton and Litter. Forty-seven patients attended the review consultation. Of these, seven were excluded because they were cases of arthrodesis, silicone prostheses or resurfacing prostheses, while 12 underwent bilateral operations.

In total, 40 patients and 52 hands were evaluated. We divided the patients into two groups, depending on the type of surgical procedure. Thirty-two hands underwent trapeziectomy alone or in association with ligamentoplasty in accordance with the technique of Sigfuson-Lundborg ${ }^{(5)}$ (group A) and 20 hands underwent ball-and-socket arthroplasty on the trapezium-metacarpal joint (group B). The inclusion criteria for arthroplasty were: female patients, good bone stock, no systemic inflammatory disease and few manual labor demands. The patients with a prosthesis were immobilized using a plaster cast for approximately two weeks, and the patients with trapeziectomy with or without ligamentoplasty were in a plaster cast for around three weeks.

The mean length of the follow-up was 72 months in group A and 23 months in group B. In group A, four male patients and 18 female patients were operated. In group B, 18 female patients were operated. The mean age at the time of the surgery was 60 years in group A and 62 years in group B (Table 1). Two patients were operated bilaterally with two different techniques (Table 2 and Figure 1).

The result from the treatment was evaluated according to clinical and radiographic criteria. The Quick Dash functional scale was used. The clinical

Table 1 - General characteristics of the patients.

\begin{tabular}{c|c|c}
\hline & Group A & Group B \\
\hline No. of patients & 22 & 18 \\
\hline No. of hands & 32 & 20 \\
\hline Sex (male/female) & $4 / 18$ & $0 / 18$ \\
\hline Mean age (years) & $60(46-76)$ & $62(46-80)$ \\
\hline Side (right/left) & $16 / 12$ & $7 / 13$ \\
\hline Follow-up (months) & $72(180-15)$ & $23(36-12)$ \\
\hline
\end{tabular}

Table 2 - Patients operated bilaterally with two different techniques.

\begin{tabular}{c|c|c}
\hline & Arthroplasty & Trapeziectomy \\
\hline Radial abduction & $72.5^{\circ}$ & $67.5^{\circ}$ \\
\hline Palmar abduction & $40^{\circ}$ & $37.5^{\circ}$ \\
\hline Grip strength & $20 \mathrm{~kg}$ & $18 \mathrm{~kg}$ \\
\hline Pinch strength & $3.8 \mathrm{~kg}$ & $3.4 \mathrm{~kg}$ \\
\hline Scaphoid-metacarpal height & $50 \mathrm{~mm}$ & $47 \mathrm{~mm}$ \\
\hline
\end{tabular}

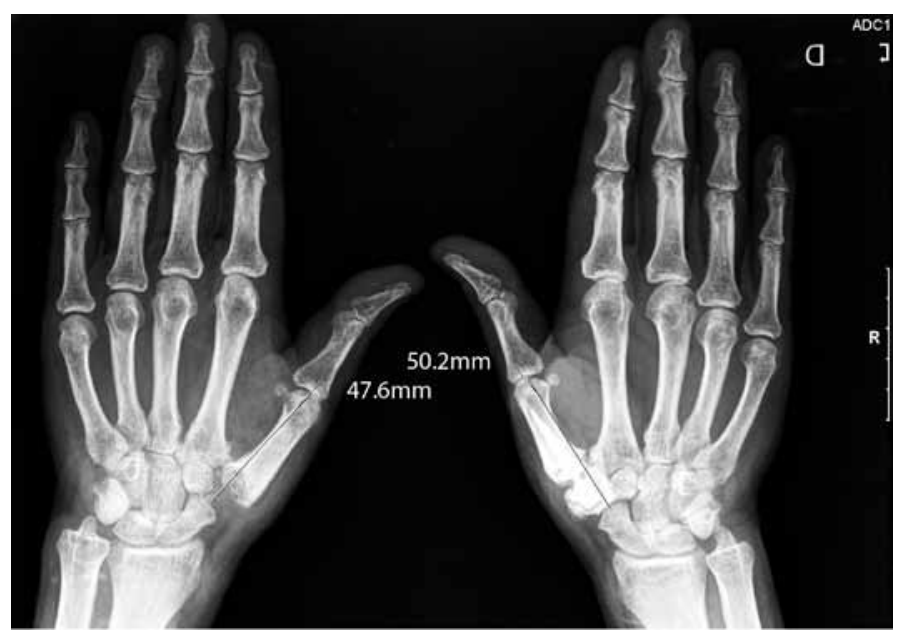

Figure 1 - Patients operated bilaterally using two different techniques.

evaluation was based on four items: pain, function, mobility and strength. Radiographic evaluations were made before and after the operation, using anterior, lateral and stress views. The height difference in the scaphoid-metacarpal column (i.e. the line joining the most distal point on the scaphoid to the most distal point on the first metacarpal) between the two hands of the same patient was calculated (Figure 2). The imaging evaluation also made it possible to assess implant placement, presence of radiolucency lines and preservation of the height of the scaphoid-metacarpal column.

Pain was assessed on a visual pain scale going from 0 to 10 points, corresponding to absence of pain and maximum pain, respectively.

The functional assessment was based on the possibility of carrying out activities of daily living, such as: picking up coins, opening a bottle top, turning a key in a lock, fastening/unfastening the buttons on a piece of clothing and writing. 
The mobility of the trapezium-metacarpal joint was measured in two directions: radial abduction and palmar abduction.

For all the patients, grip and pinch strength were measured using the same dynamometer (Jamar $\mathbb{R}$ Hand Dynamometer - 5030J1).
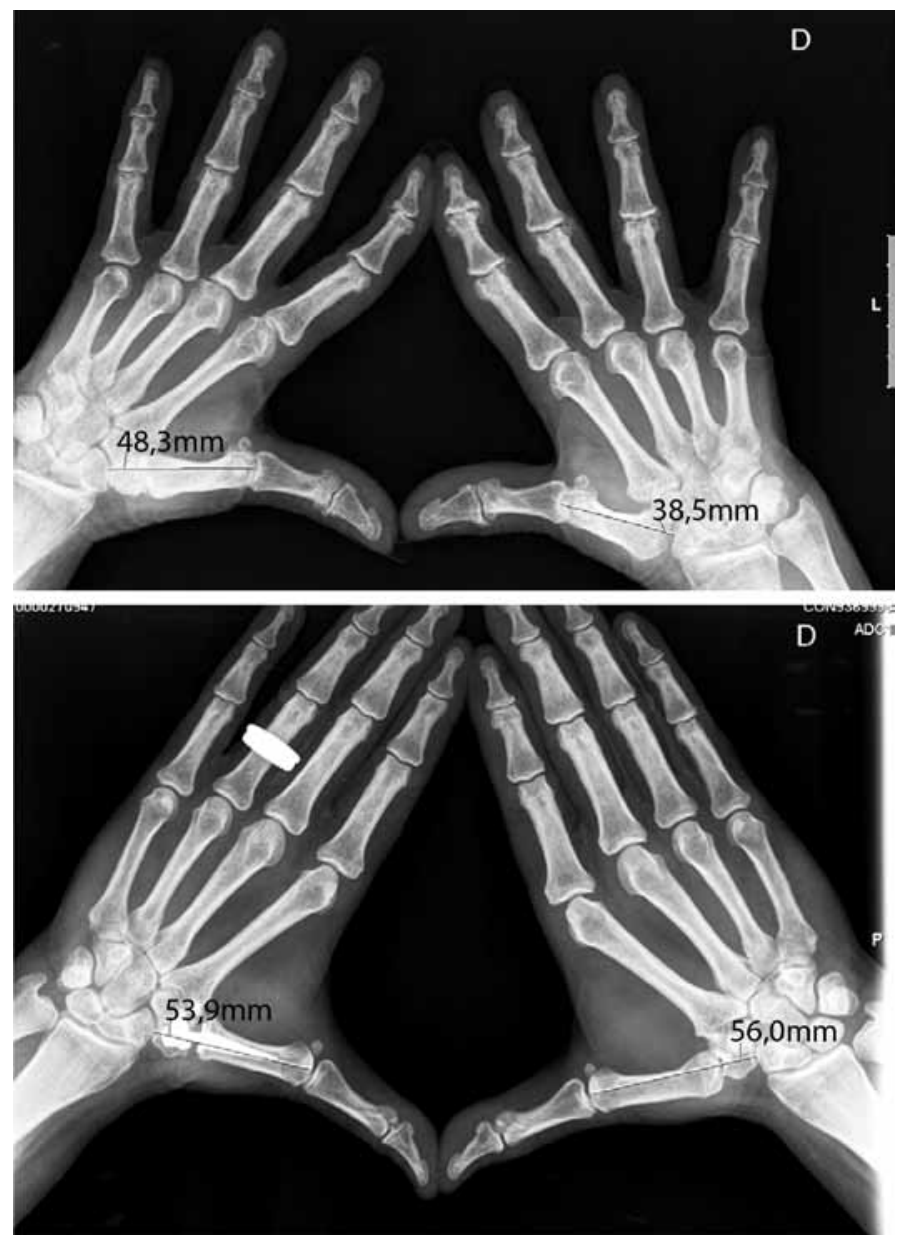

Figure 2 - Measurement of the difference in the scaphoid-metacarpal column between the operated and non-operated hands.

\section{RESULTS}

The results relating to pain (Table 3 ), activities of daily living (Table 4) and thumb mobility and strength (Table 5) did not differ significantly between the two groups.

Regarding the height of the scaphoid-metacarpal column, we found that the difference between the operated and non-operated hands was an average of $-0.269 \mathrm{~cm}$ in group A and $0.036 \mathrm{~cm}$ in group B. In other words, there was a decrease in the height of the scaphoid-metacarpal column in the trapeziectomy group and preservation of the height in the prosthesis group.
Table 3 - Assessment of thumb pain.

\begin{tabular}{c|c|c}
\hline & Group A & Group B \\
\hline Without pain & $86 \%$ & $82 \%$ \\
\hline Pain on mobilization & $10 \%$ & $13 \%$ \\
\hline Pain when resting & $4 \%$ & $5 \%$ \\
\hline Pain at night & - & - \\
\hline Pain scale & 1.3 & 2.1 \\
\hline
\end{tabular}

Table 4 - Activities of daily living.

\begin{tabular}{c|c|c|c|c}
\hline \multirow{2}{*}{} & \multicolumn{2}{|c|}{ Without difficulty } & \multicolumn{2}{c}{ With difficulty } \\
\cline { 2 - 5 } & Group A & Group B & Group A & Group B \\
\hline Picking up coins & $81 \%$ & $89 \%$ & $19 \%$ & $11 \%$ \\
\hline Opening lids & $48 \%$ & $44 \%$ & $52 \%$ & $56 \%$ \\
\hline Turning keys & $81 \%$ & $72 \%$ & $19 \%$ & $28 \%$ \\
\hline Writing & $95 \%$ & $89 \%$ & $5 \%$ & $11 \%$ \\
\hline Using a knife & $86 \%$ & $72 \%$ & $14 \%$ & $18 \%$ \\
\hline
\end{tabular}

Table 5 - Thumb mobility and strength.

\begin{tabular}{c|c|c|c|c}
\hline \multirow{2}{*}{} & \multicolumn{2}{|c|}{ Group A } & \multicolumn{2}{c}{ Group B } \\
\cline { 2 - 5 } & $\begin{array}{c}\text { Operated } \\
\text { hands }\end{array}$ & $\begin{array}{c}\text { Non- } \\
\text { operated } \\
\text { hands }\end{array}$ & $\begin{array}{c}\text { Operated } \\
\text { hands }\end{array}$ & $\begin{array}{c}\text { Non- } \\
\text { operated } \\
\text { hands }\end{array}$ \\
\hline Radial abduction & $67^{\circ}$ & $64^{\circ}$ & $68^{\circ}$ & $66^{\circ}$ \\
\hline Palmar abduction & $50^{\circ}$ & $47,5^{\circ}$ & $38^{\circ}$ & $36^{\circ}$ \\
\hline Grip strength (kg) & 17.4 & 14.8 & 17.1 & 16.1 \\
\hline Pinch strength (kg) & 4.3 & 3.5 & 4.1 & 3.9 \\
\hline
\end{tabular}

Regarding the recovery time, the patients in group A required an average of 10 weeks to return to their activities of daily living, and group B, 4.5 weeks.

Two patients were operated bilaterally with two different techniques. The hand that underwent arthroplasty with an implant presented better radial and palmar abduction, greater grip and pinch strength and greater scaphoid-metacarpal height (Table 2 and Figure 1).

The radiographic evaluation of the prostheses showed heterotopic calcification and three cases of peritrapezial radiolucent lines. Only one case presented pain on mobilization, while all the other patients were asymptomatic and satisfied with their treatment.

Four cases of complications were registered: one case of algoneurodystrophy in group A and two dislocations and one fracture of the trapezium 
in group B. Only one patient required revision surgery. The algoneurodystrophy was resolved after one year of medical treatment. One dislocation was treated using closed reduction and other, using open reduction and removal of the volar osteophyte of the trapezium. The fracture of the trapezium was detected intraoperatively while inserting the implant and was treated postoperatively by means of immobilization, with good evolution.

The mean score on the Quick Dash scale was 45.6 in group A and 41.7 in group B.

The degree of subjective satisfaction was comparable between the two groups (Table 6).

Table 6 - Patients' subjective degree of satisfaction.

\begin{tabular}{c|c|c}
\hline & Group A & Group B \\
\hline Degree of satisfaction & $90 \%$ very satisfied & $90 \%$ very satisfied \\
\hline $\begin{array}{c}\text { Wished to have the } \\
\text { contralateral hand } \\
\text { operated }\end{array}$ & $82 \%$ & $90 \%$ \\
\hline $\begin{array}{c}\text { Would recommend the } \\
\text { surgical procedure }\end{array}$ & $94 \%$ & $90 \%$ \\
\hline
\end{tabular}

\section{DISCUSSION}

The two techniques (trapeziectomy with or without ligamentoplasty versus total prosthesis) did not differ significantly regarding pain, mobility, strength and dexterity in activities of daily living ${ }^{(4,6)}$. The small differences found between the two groups were perhaps related to the difference in follow-up between them. The patients who underwent trapeziectomy with or without ligamentoplasty had a longer followup, through which they may have had more time for adaptation.

Arthroplasty with placement of an implant enables maintenance of the scaphoid-metacarpal colu$\mathrm{mn}$, although it has not been possible to correlate this with better clinical results and greater stability ${ }^{(7)}$. It is more costly and has a greater risk of complications, namely dislocation and detachment ${ }^{(8)}$. It should be noted that we found a complication rate of $15 \%$ in the prosthesis group, of which $10 \%$ (two patients) were cases of dislocation, of which only one case required surgical revision.

The great advantage of arthroplasty with placement of an implant is the earlier return to activities of daily living ${ }^{(9,10)}$.

It was not within the scope of this study to compare trapeziectomy alone with trapeziectomy associated with ligamentoplasty, or to compare different types of implants.

\section{CONCLUSION}

Arthroplasty with placement of an implant for treating rhizarthrosis is an attractive proposition because of the rapid recovery that it provides. However, it needs to be carefully applied, since its long-term results and the surgical revision rate remain unknown. In the authors' opinion, it should be reserved for women aged over 60 years and should be avoided among young patients and among men with demanding daily activities.

\section{REFERENCES}

1. de la Caffinière JY. Prothèse totale trapézio-métacarpienne._Rev Chir Orthop Reparatrice Appar Mot. 1974 Jun;60(4):299-308.

2. Nicholas RM, Calderwood JW. De la Caffinière arthroplasty for the basal thumb joint osteoarthritis. J Bone Joint Surg Br. 1992;74(2):309-12.

3. Pellegrini VD Jr, Burson RI. Surgical management of the basal joint arthritis of the thumb: Part I. Long-term results of silicone implant arthroplasty. J Hand Surg Am. 1986;11(3):309-24.

4. Brutus JP, Kinnen L. Remplacement prothétique total de la trapézométacarpienne au moyen de la prothèse ARPE dans le traitement de la rhizarthrose: notre expérience à court terme dans une série personnelle de 63 cas consécutifs. Chir Main. 2004;23(5):224-8.

5. Sigfusson R, Lundborg G. Abductor pollis longus tendon arthroplasty for treatment of the arthrosis in the first carpometacarpal joint. Scand J Plast Reconstr Surg Hand Surg. 1991;25(1):73-7.

6. Moutet F, Lignon J, Oberlin C, Alnot JY, Sartorius C. Les prothèses totales trapézo-métacarpiennes. Résultats de l'étude multicentrique (106 cas). Ann Chir Main Memb Super. 1990;9(3):189-94.

7. kadiyala RK, Gelbermann RH, Kwon B. Radiografic assessment of the trapezial space before and after ligament reconstruction and tendon interposition arthroplasty. J Hand Surg Br. 1996;21(2):177-81.

8. Van Capelle HGJ, Elzenga P, Von Horn JR. Long-term results and loosening analysis of the De La Caffinière replacements of the trapeziometacarpal joint. J Hand Surg Am. 1999;24(3):476-82.

9. Wahl SW, Sunward GR. Non-cemented replacement of the trapeziometacarpal joint. J Bone Joint Surg Br. 1996;78(5):787-92.

10. Wachtl SW, Guggenheim PR, Sennwald GR. Cemented and non-cemented replacements of the trapeziometacarpal joint. J Bone Joint Surg Br. 1998;80(1):121-5. 